\title{
Adsorptive Stripping Voltammetric Determination of Bupropion in Pharmaceuticals
}

\author{
RAM LAL SAINI, SACHIN DOI, K. K. JHANKAL and D. K. SHARMA* \\ Electrochemical Sensor Research Laboratory, Department of Chemistry, \\ University of Rajasthan, Jaipur (Rajasthan)- 302004, India \\ sharmadkuor@gmail.com
}

Received 30 December 2016 / Accepted 15 January 2017

\begin{abstract}
Electrochemical studies of bupropion by voltammetric techniques were carried out. The bupropion gave one well-defined reduction peak at -1.2 to $-1.3 \mathrm{~V}$ vs. $\mathrm{Ag} / \mathrm{AgCl}$ electrode in Britton Robinson buffer BR of $\mathrm{pH}$ 9. Under optimized conditions, a linear response was obtained between $1.0 \times 10^{-6} \mathrm{M}$ to $5.6 \times 10^{-6} \mathrm{M}$ in aqueous media for square wave and differential pulse cathodic adsorptive stripping voltammetric techniques. The electrochemical process was diffusion controlled. The value of limit of detection (LOD) are $1.28 \times 10^{-7} \mathrm{~mol} \mathrm{~L}^{-1}$ and $7.79 \times 10^{-7} \mathrm{~mol} \mathrm{~L}^{-1}$ for SWCAdSV and DPCAdSV respectively.
\end{abstract}

Keywords: Bupropion, Anti-depressant, Cyclic voltammetry, Glassy carbon electrode, Square wave voltammetry

\section{Introduction}

Bupropion (BUP) (Figure 1) is an aminoketone derivative which is widely used as an antidepressant in the pharmacotherapy for smoking cessation. BUP is metabolised to three active metabolites; hydroxybupropion, the major metabolite, threohydrobupropion and erythro hydrobupropion ${ }^{1}$. Also, in vitro studies the potency of HBUP was found to be comparable to that of BUP. The metabolites of threohydrobupropion and erythro hydrobupropion were evaluated as total concentration because of their lower concentration compared to HBUP and additionally the potency of these were one-fifth as potent as $\mathrm{BUP}^{2-5}$.<smiles>CC(NC(C)(C)C)C(=O)c1cccc(Cl)c1</smiles>

Figure 1. Chemical structure of Bupropion 
The analysis of BUP in biological fluids ${ }^{6-12}$ and in pharmaceuticals has been performed with liquid chromatography, liquid chromatography-mass spectrometry electrokinetic chromatography and thin layer chromatography ${ }^{13-15}$. Also, several studies including chiral separations of BUP and HBUP enantiomers were described ${ }^{16-18}$. Using Cooper's method, BUP stability in human plasma has been reported ${ }^{19}$.

There has been no differential pulse and square wave cathodic adsorptive stripping voltammetric study published on quantitative determination of bupropion in spiked human urine. The present paper deals with the voltammetric analysis of bupropion in pharmaceuticals with a low detection limit. The low value of limit of detection (LOD) validates the analytical procedure and provides a fast and reliable technique for the assay of the sample without consuming excess time.

\section{Experimental}

Bupropion was purchased from the Cipla Pvt Ltd and was used without purification. A stock standard solution of bulk bupropion $\left(1 \times 10^{-4} \mathrm{M}\right)$ was prepared in ethanol and preserved at $4{ }^{\circ} \mathrm{C}$ until assessment. A series of BR buffer of $\mathrm{pH}$ values 4 to 13 was prepared and used as a supporting electrolyte. Deionised water was used to prepare all the solutions. The working solutions were prepared by a fix volume of stock solution and buffers. Reagents were used of analytical grade.

\section{Instrumentation}

Model 1230A (SR 400) electrochemical analyser (CHI Instrument, USA) was employed for electrochemical techniques, with a totally automated attached to a PC with proper $\mathrm{CHI}$ $100 \mathrm{~W}$ version 2.3 software for total control of the experiments and data acquisition and treatment. A cell system containing three electrodes was used with working electrode as activated glassy carbon electrode, reference electrode as $\mathrm{Ag} / \mathrm{AgCl}(3 \mathrm{M} \mathrm{KCl})$ and auxiliary electrode as the platinum wire. A digital $\mathrm{pH}$-meter (CHINO-DB-1011) fitted with a glass electrode standardized with buffers of known $\mathrm{pH}$ was used for measuring the $\mathrm{pH}$ values of the solutions.

\section{General procedure}

For total $10 \mathrm{~mL}$ solution, BR buffer of $\mathrm{pH} 9.0$ and the appropriate concentration of the bupropion were introduced into the electrochemical cell and purged with pure deoxygenated nitrogen for 10-15 minutes under stirred conditions. These results to remove oxygen gas before measurements. Electrochemical pre-treatment was always performed in the same solution in which the measurement was subsequently carried out. The working glassy carbon electrode was polished $0.05 \mu \mathrm{m}$ aluminium oxide and sonicated for a short time to remove impurities on the electrode surface and then it was dried in an oven at $40{ }^{\circ} \mathrm{C}$. The accumulation of bupropion at the working electrode was carried out for 15 to 20 seconds while the solution was stirred at $2000 \mathrm{rpm}$. After optimization of operational parameters the cyclic and stripping voltammograms were recorded.

\section{Results and Discussion}

Electrochemical studies of bupropion were performed by using cyclic voltammetry (CV), square wave cathodic adsorptive stripping voltammetry (SWCAdSV) and differential pulse cathodic adsorptive stripping voltammetry (DPCAdSV). In all electrochemical methods bupropion gave one well defined reduction peak at $-1.25 \mathrm{~V} v s . \mathrm{Ag} / \mathrm{AgCl}$ reference electrode. 


\section{Cyclic voltammetric behaviour}

The cyclic voltammogram of bupropion in britton robinson buffers ( $\mathrm{pH} 4-13)$ exhibits one well-defined reduction peak in the potential range of $-0.5-0$ to $-1.5 \mathrm{~V}$ versus $\mathrm{Ag} / \mathrm{Agcl}$ reference electrode at concentration $1 \times 10^{-5}$ and scan rates 50-175. No peak could be observed in the anodic direction, suggesting the irreversible nature of the electrode process.

\section{Effect of scan rate}

The voltammetric investigations at various scan rates were performed under the optimum conditions (Figure 2). As the scan rate increases gradually from the range 50 to $175 \mathrm{mV} / \mathrm{s}$ at fixed concentration of bupropion, the background signal decreases and peak potential shifted towards more negative value with increase in current confirming the irreversible nature of the reduction process ${ }^{20-24}$. Furthermore, peak current (Ip) found to be linear dependent on square root of scan rate related with the Randles - Servick equation, which can be expressed as:

$$
\mathrm{Ip}=\left(2.99 \times 10^{5}\right) \mathrm{n}[\mathrm{\alpha n}]^{1 / 2} \mathrm{~A} \mathrm{C}_{\mathrm{o}} \mathrm{D}_{\mathrm{o}}^{1 / 2} v^{1 / 2}
$$

Where $\mathrm{n}$ is the number of electrons exchange in reduction, $\alpha$ is the charge transfer coefficient, $A\left(\mathrm{~cm}^{2}\right)$ is the apparent surface area of the electrode, $\mathrm{C}_{\mathrm{o}}(\mathrm{mol} / \mathrm{L})$ is the concentration of the electro-active species, Ip $(\mu \mathrm{A})$ is the cathodic peak current, $D_{0}\left(\mathrm{~cm}^{2} / \mathrm{s}\right)$ is the diffusion coefficient of the electroactive species and $v(\mathrm{mV} / \mathrm{s})$ is the scan rate.

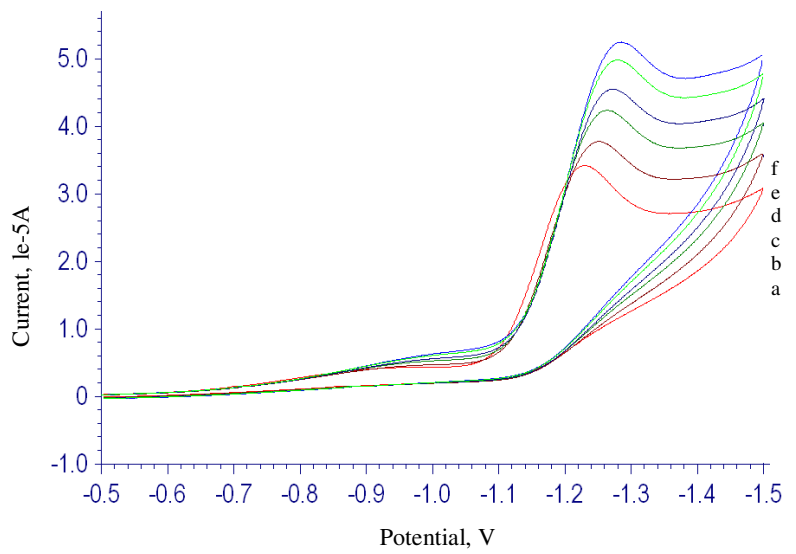

Figure 2. Cyclic voltammogram of $1 \times 10^{-6} \mathrm{M}$ Bupropion in Britton-Robinson buffer at different scan rates: (a) $50 \mathrm{mV}^{-1}$ (b) $75 \mathrm{mV}^{-1}$ (c) $100 \mathrm{mV}^{-1}$ (d) $125 \mathrm{mV}^{-1}$ (e) $150 \mathrm{mV}^{-1}$ (e) 175 $\mathrm{mV}^{-1}$ at $\mathrm{pH} 9.0$

A straight line was observed having a slope 0.077 when peak potential $(\mathrm{Ep} / \mathrm{V})$ were plotted (Figure 3) against $\log v\left(\mathrm{mVs}^{-1}\right)$ at $\mathrm{pH}$ value of 9.0 at concentration $1.0 \times 10^{-5}$ can be expressed by the equation

$$
\mathrm{Ep}=0.077 \log v+1.109(\mathrm{~V}) \quad \mathrm{R}^{2}=0.993
$$

The effect of scan rate $\left(v^{1 / 2}\right)$ on peak current (Ip) was examined. A graph between peak current (Ip) versus square root of scan rate $\left(v^{1 / 2}\right)$ gave a straight line that expressed by the equation

$$
\operatorname{Ip}(\mu \mathrm{A})=0.222 v^{1 / 2}(\mathrm{mV} / \mathrm{s})+1.346(\mu \mathrm{A}) \quad \mathrm{R}^{2}=0.994
$$

As the scan rate was increased from 50 to $175 \mathrm{mVs}^{-1}$ at affix concentration of bupropion, the peak current increased steadily and the peak current function $\left(\mathrm{Ip} / \mathrm{v}^{1 / 2}\right)$ exhibited nearly constancy ${ }^{25-30}$. 
The linear relationship existing between peak current (Ip) and square root of the scan rate $\left(v^{1 / 2}\right)$ with a slope 0.222 showed that the reduction process is predominantly diffusion controlled in the whole scan rate range studied ${ }^{31-35}$ (Figure 4).

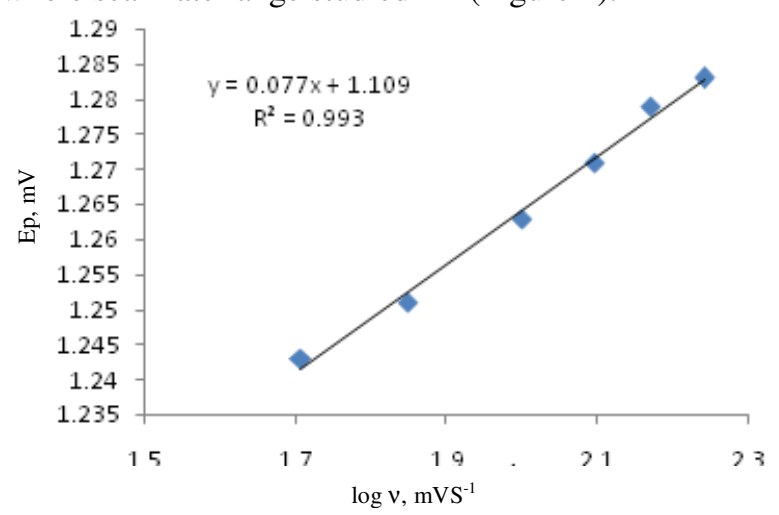

Figure 3. Influence of scan rate $(\log v(\mathrm{mV} / \mathrm{s}))$ on peak potential $(\mathrm{Ep} / \mathrm{V})$ of cyclic voltammograms of bupropion in BR buffer of $\mathrm{pH} 9.0$

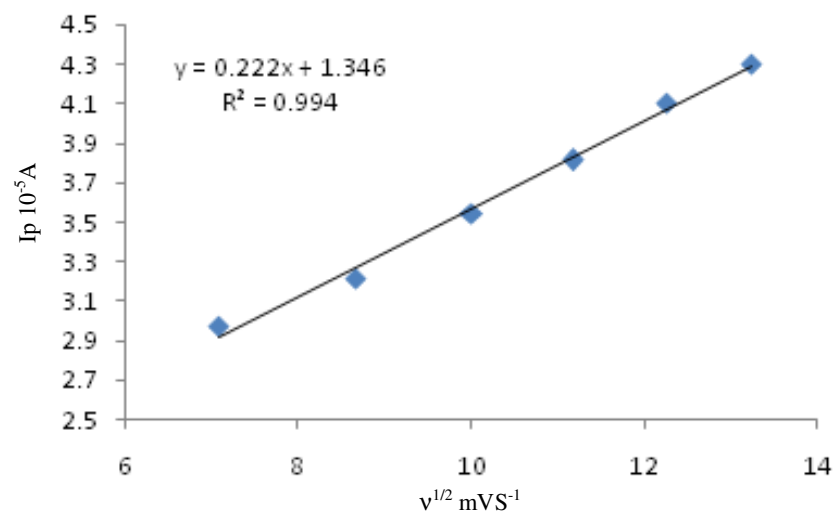

Figure 4. Influence of root of scan rate $\left(v^{1 / 2}(\mathrm{mV} / \mathrm{s})\right)$ on peak current $(\mathrm{Ip} / \mu \mathrm{A})$ of cyclic voltammograms of bupropion in BR buffer of $\mathrm{pH} 9.0$

\section{Effect of $p H$}

The peak current closely depend on the $\mathrm{pH}$ of the buffer solution. The cathodic peak current (Ip) reaches maximum value at $\mathrm{pH} 9$, after that it decreases. The effect of $\mathrm{pH}$ on peak current was studied in the range 4-13 at scan rate of $100 \mathrm{mV} / \mathrm{s}$. The effect of $\mathrm{pH}$ of supporting electrolyte on peak current shows in Figure 5.

\section{Square wave cathodic adsorptive stripping voltammetric studies}

The best result with respect to signal evaluation and peak shape accompanied by sharper response was obtained with BR buffer at $\mathrm{pH}$ 9. This supporting electrolyte was chosen for the subsequent experiments. In order to develop a voltammetric method for the trace element study of the bupropion in pharmaceuticals Square Wave Cathodic Adsorptive Stripping Voltammetry (SWCAdSV) was developed. SWCAdSV is effective and quick electro-analytical technique with well-established advantages, including good discrimination against background current, high sensitivity, substantial speed and low detection limits. 


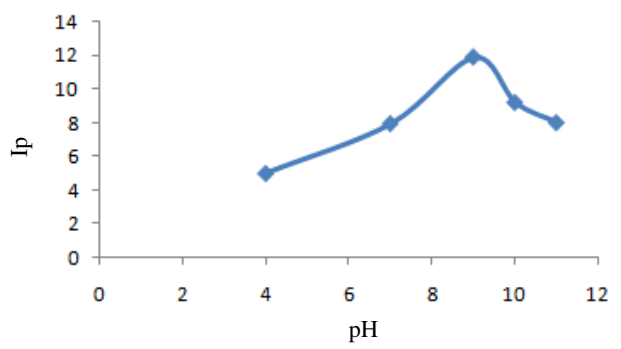

Figure 5. Effect of $\mathrm{pH}$ of medium on cathodic peak current

\section{Validation of the procedure}

Validation of the proposed SWCAdSV technique for the analysis of bupropion in pharmaceutical dosages forms was carried out via estimation of the range of linearity, the limit of detection (LOD) and the limit of quantification (LOQ). The applicability of the proposed SWCAdSV procedure as analytical methods for the determination of bupropion was examined by measuring the peak current of stripping mode. The square wave cathodic adsorptive voltammograms of bupropion at concentration over the $1.0 \times 10^{-6} \mathrm{M}$ to $5.6 \times 10^{-6} \mathrm{M}$ are shown in Figure 6. The linear regression equation is expressed as

$$
\mathrm{Ip}(\mu \mathrm{A})=4.181 \mathrm{C}(\mu \mathrm{M})+0.357(\mu \mathrm{A}) \quad \mathrm{R}^{2}=0.990
$$

The regression plot showed that there is a linear dependence of the current intensity on concentration in SWCAdSV technique over the $1.0 \times 10^{-6} \mathrm{M}$ to $5.6 \times 10^{-6} \mathrm{M}$ shows in Figure 7.

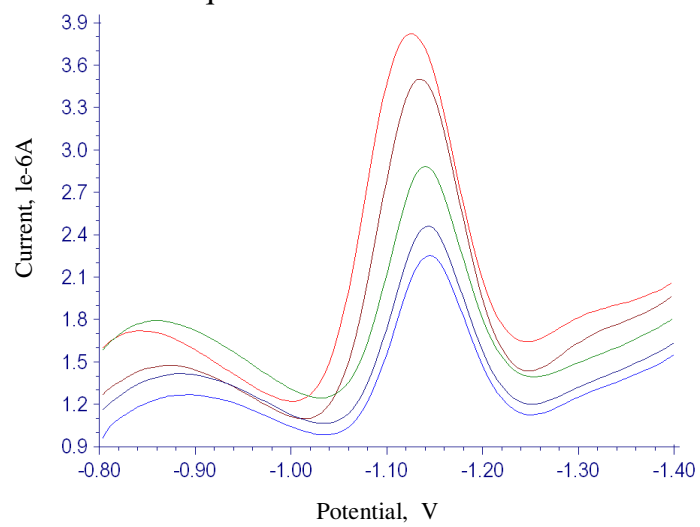

Figure 6. SWCAdS voltammograms of bupropion at different concentrations

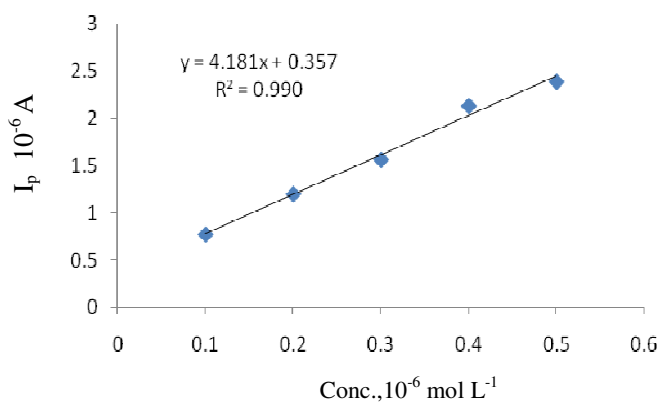

Figure 7. Plot of peak current vs. concentration from SWCAdS voltammograms 


\section{Sensitivity / Detection limit}

The limit of detection (LOD) is an important quantity in chemical analysis. The LOD is the smallest concentration or amount that can be detected with reasonable certainty for a given analytical procedure All the analytical data are shown in the Table 1. The detection limit was calculated by the equation ${ }^{36-38}$.

$$
\mathrm{LOD}=3 \mathrm{SD} / b \text {, }
$$

Where SD is the standard deviation of the peak currents (five runs) and $b$ is the slope of the calibration curve. The calculated detection limit for the standard solution was $1.28 \times 10^{-7} \mathrm{M}$.

\section{Quantification limit}

The limit of quantification (LOQ) is the lower limit of concentration for precise quantitative measurements. The quantification limit was examined by the equation

$$
\mathrm{LOQ}=10 \mathrm{SD} / b \text {. }
$$

The limit of quantification for the standard solution was found to be $4.26 \times 10^{-7} \mathrm{M}$.

Table 1. Analytical parameters of determination of Bupropion by using SW-CAdSV and DP-CAdSV methods

\begin{tabular}{ccc}
\hline Parameters & SWCAdSV & DPCAdSV \\
\hline Linearity Range $(\mathrm{M})$ & $1 \times 10^{-6}$ to $5.6 \times 10^{-6}$ & $1 \times 10^{-6}$ to $5.6 \times 10^{-6}$ \\
Slope $(\mathrm{A} / \mathrm{M})$ & 4.181 & 1.829 \\
Intercept $(\mu \mathrm{A})$ & 0.357 & 1.042 \\
LOD $(\mathrm{M})$ & $1.28 \times 10^{-7}$ & $7.79 \times 10^{-7}$ \\
LOQ $(\mathrm{M})$ & $4.26 \times 10^{-7}$ & $2.59 \times 10^{-6}$ \\
Standard Deviation & 0.1784 & 0.4755 \\
Correlation Coefficient $\left(\mathrm{R}^{2}\right)$ & 0.990 & 0.995 \\
\hline
\end{tabular}

\section{Differential pulse cathodic adsorptive stripping voltammetric studies}

The differential pulse cathodic adsorptive stripping voltammograms are shown in Figure 7 over the concentration range $1 \times 10^{-6}$ to $5.6 \times 10^{-6} \mathrm{M}$. The linear regression equation is expressed as

$$
\operatorname{Ip}(\mu \mathrm{A})=1.829 \mathrm{C}(\mu \mathrm{M})+1.042(\mu \mathrm{A}) \quad \mathrm{R}^{2}=0.995
$$

The regression plot (Figure 8) showed that there is a linear dependence of the current intensity on concentration. The calculated detection limit for the standard solution was $7.79 \times 10^{-7} \mathrm{M}$. The limit of quantification was found to be $2.59 \times 10^{-6} \mathrm{M}$.

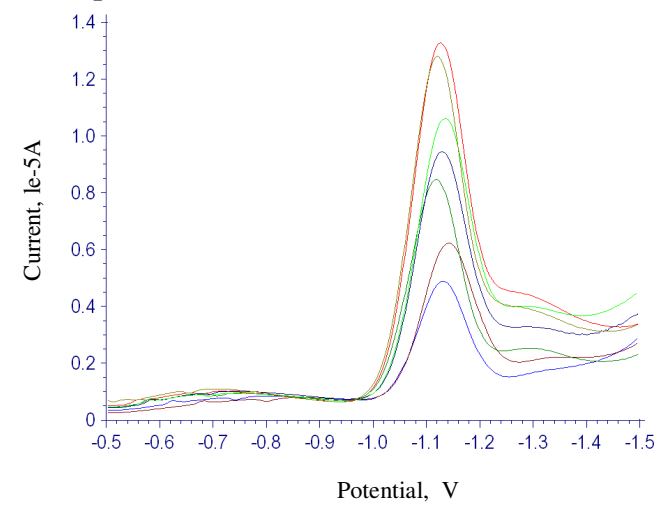

Figure 7. DPCAdS voltammograms of bupropion at different concentrations 


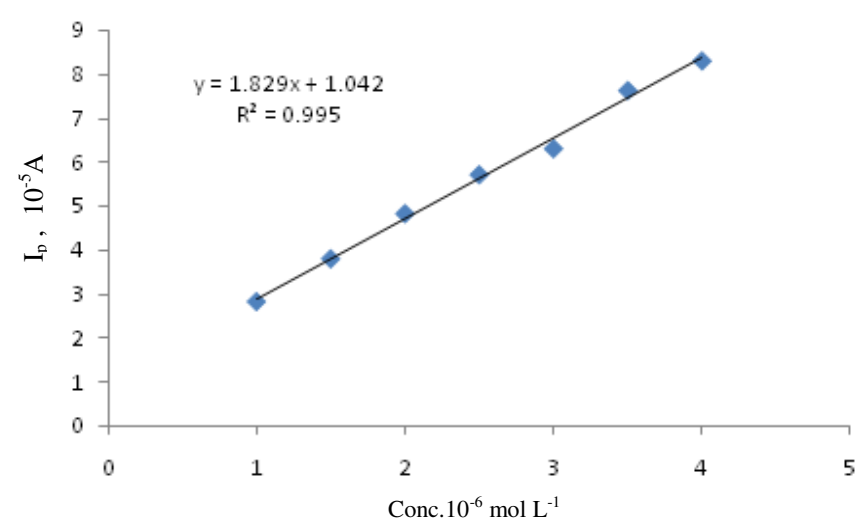

Figure 8. Plot of peak current vs. concentration from DPCAdS voltammograms

\section{Conclusion}

The electrochemical response of bupropion at the surface of glassy carbon electrode was studied by the of CV, DPCAdSV and SWCAdSV techniques. The electrochemical reduction of bupropion at glassy carbon electrode under the optimized conditions is diffusion controlled. A validate square wave stripping voltammetric procedure was developed and successfully applied to the estimation of bupropion in pharmaceutical formulation. These methods are reliable, rapid and relatively inexpensive to operate compared with alternative methods. They are suitable for routine analysis in quality control laboratories.

\section{Acknowledgment}

The authors would like to thank Head, Department of Chemistry, University of Rajasthan, Jaipur for providing necessary facilities.

\section{References}

1. Richmond R and Zwar N, Drug Alcohol Rev., 2003, 22(22), 203-220; DOI:10.1080/09595230100100642

2. Jefferson J W, Pradko J F and Muir K T, Clin Ther., 2005, 27(11), 1685-1695; DOI:10.1016/j.clinthera.2005.11.011

3. Hsyu P H, Singh A, Giargiari T D, Dunn J A, Ascher J A and Johnston J A, J Clin Pharmacol. 1997, 37)(8), 737-743; DOI:10.1002/j.1552-4604.1997.tb04361.x

4. Stewart J J, Berkel H J, Parish R C, Simar M R, Syed A, Bocchini J A, Wilson J T and Manno J E, J Clin Pharmacol., 2001, 41(7), 770-778; DOI:10.1177/00912700122010564

5. Johnston J A, Ascher J, Leadbetter R L, Schmith V D, Patel D K, Durcan M and Bentley B, Drugs, 2002, 62, 11-24.

6. Loboz K K, Gross A S, Ray J and McLachlan A J, J Chromatogr B, 2005, 823(B), 115-121; DOI:10.1016/j.jchromb.2005.06.009

7. Cooper T B, Suckow R F and Glassman A, J Pharm Sci., 1984, 73(8), 1104-1107; DOI:10.1002/jps.2600730820

8. Suckow R F, Smith T M, Perumal A S, and Cooper T B, Drug Metab Dispos., 1986, 14, 692-697;

9. Zhang D, Yuan B, Qiao M and Li F, J Pharm Biomed Anal., 2003, 33, 287-293; DOI:10.1016/S0731-7085(03)00314-5 
10. Yeniceli D and Dogrukol-Ak D, Chromatographia, 2009, 70(11), 1703-1708;

DOI:10.1365/s10337-009-1361-z

11. Borges V, Yang E, Dunn J and Henion J, J Chromatogr., 2004, 804 (B), 277-287; DOI:10.1016/j.jchromb.2004.01.024

12. Coles R and Kharasch E D, J Chromatogr., 2007, 857(1)(B), 67-75; DOI:10.1016/j.jchromb.2007.07.007

13. Castro-Puyana M, Garcia M A and Marina M L, J Chromatogr., 2008, 875(B), 260265; DOI:10.1016/j.jchromb.2008.09.008

14. Yeniceli D and Dogrukol-Ak D, Chromatographia, 2010, 71(1), 79-84; DOI:10.1365/s10337-009-1410-7

15. Yeniceli D and Dogrukol-Ak D, J Planar Chromatogr., 2010, 23(3), 212-218; DOI:10.1556/JPC.23.2010.3.9

16. Suckow R F, Zhang M F and Cooper T B, Biomed Chromatogr., 1997, 11(3), 174179; DOI:10.1002/(SICI)1099-0801(199705)11:3<174::AID-BMC681>3.0.CO;2-E

17. Munro J S and Walker T A, J Chromatogr., 2001, 913(1-2)(A), 275-282; DOI:10.1016/S0021-9673(01)00639-2

18. Munro J S, Gormley J P and Walker T A, J Liq Chromatogr Relat Technol., 2001, 24(3), 327-339; DOI:10.1081/JLC-100001337

19. Laizure S C and DeVane C L, Ther Drug Monit., 1985, 7(4), 447-450.

20. Dufresne R L, Weber S S and Becker Robert E, Annals of Pharmacotherapy, 1984, 18(12).

21. Al-Meshal M A, Ramadan M A, Lotfi K M and Shibl A M, J Clin Pharm Ther., 1995, 20(3), 159-163; DOI:10.1111/j.1365-2710.1995.tb00642.x

22. Kauffmann J M and Viré J C, Anal Chim Acta, 1993, 273(1-2), 329-337; DOI:10.1016/0003-2670(93)80173-I

23. Uslu B, Ozkan S A and Sentürk Z, Anal Chim Acta, 2006, 555(2), 341-347; DOI:10.1016/j.aca.2005.09.034

24. Kumari M and Sharma D K, J Korean Chem Soc., 2011, 55(1), 50-56; DOI:10.5012/jkcs.2011.55.1.050

25. Mourya G L, Jhankal K K, Parashar P and Sharma D K, Der Pharm Sinica, 2012, 3(6), 708-714.

26. Uslu B, Dogan B, Ozkan S A and Aboul-Enein H Y, Anal Chim Acta., 2005, 55(1-2), 127-134; DOI:10.1016/j.aca.2005.07.040

27. Wang J, Electroanalytical Chemistry, Wiley-VCH Publication, New York, 2006, 167.

28. Bard A J and Faulkner L R, Electrochemical Methods: Fundamentals and Applications, John Wiley \& Sons. Inc., New York, 2001.

29. Kissinger $\mathrm{P} T$ and Heinman W R, Laboratory Techniques in Electroanalytical Chemistry, Marcel Dekker, New York, 1996.

30. Gosser D K, Cyclic Voltammetry, VCH, New York, 1993.

31. Ozkan S A, Uslu B, and Aboul-Enein H Y, Crit Rev Anal Chem., 2003. 33(3), 155-181; DOI:10.1080/713609162

32. Sharma D K, Mourya G L, Jhankal K K, Jones L A and Bhargava S K, Der Pharm Lettre, 2012, 4(5), 1599-1606.

33. Jhankal K K, Sharma A, Ramswaroop and Sharma D K, J Pharma Sci Res., 2015, 7(1), 10-13.

34. Sivaprasad M, Dhananjayulu M, and Jayapal M R and Sreedhar N Y, J Anal Bioanal. Technol., 2014, 5, 192; DOI:10.4172/2155-9872.1000192 
35. Laviron E, Roullier L and Degrand C, J Electroanal Chem Interfacial Electrochem., 1980, 112(1), 11-23; DOI:10.1016/S0022-0728(80)80003-9

36. Niranjana E, Naik R R, Kumarswamy B E, Sherigara B S and Jayadevappa H, Int J Electroanal Sci., 2007, 2, 923.

37. Swartz M E and Krull I S, Analytical Method Development and Validation, Marcel Dekker, New York, 1997.

38. Sinha P, Shekhawat A and Sharma D K, Reports Electrochem,, 2015, 5, 21-28; DOI:10.2147/RIE.S90750 